\title{
16p11.2p12.2 microduplication syndrome
}

INSERM

\section{Source}

INSERM. (1999). Orphanet: an online rare disease and orphan drug data base.

16p11.2p12.2 microduplication syndrome. ORPHA:261204

16p11.2p12.2 microduplication syndrome is a rare chromosomal anomaly syndrome resulting from the partial duplication of the short arm of chromosome 16 with a highly variable phenotype typically characterized by developmental/psychomotor delay (particularly of speech), intellectual disability, autism spectrum disorder and/or obsessive and repetitive behavior, behavioral problems (such as aggression and outbursts), dysmorphic facial features (triangular face, deep set eyes, broad and prominent nasal bridge, upslanting or narrow palpebral features, hypertelorism). Additionally, finger/hand anomalies, short stature, microcephaly and slender build are frequently described. 